\title{
Inhibiting the hexosamine biosynthetic pathway lowers O-GIcNAcylation levels and sensitizes cancer to environmental stress.
}

Lisa A. Walter, ${ }^{\#}$ Yu Hsuan Lin, ${ }^{1 \#}$ Christopher J. Halbrook, ${ }^{2}$ Kelly N. Chuh, ${ }^{1}$ Lina He, ${ }^{3}$ Nichole J. Pedowitz, ${ }^{1}$ Anna R. Batt, ${ }^{1}$ Caroline K. Brennan, ${ }^{1}$ Bangyan L. Stiles, ${ }^{3}$ Costas A. Lyssiotis, $, 2,4,5$ and Matthew R. Pratt $1,4,6, *$

Departments of ${ }^{1}$ Chemistry, ${ }^{3}$ Pharmacology and Pharmaceutical Sciences, and ${ }^{6}$ Biological Sciences, University of Southern California, Los Angeles, CA 90089.

Departments of 2 Molecular and Integrative Physiology and ${ }^{4}$ Internal Medicine, and the 5 Rogel Cancer Center, University of Michigan, Ann Arbor, MI 48109.

*Correspondence should be addressed to matthew.pratt@usc.edu

\#These authors contributed equally

\section{Supporting Information}

Table of Contents:

Figure S1. GlcNAc supplementation at $10 \mathrm{mM}$ maintains cell growth with GFAT KO.

Page S2

Figure S2. N-linked glycosylation is more resistant than O-GlcNAc to GFAT inhibition.

Page S2

Figure S3. GFAT inhibition reduces flux through the hexosamine biosynthetic pathway.

Page S3

Figure S4. NMR characterization of GFAT inhibitor R28.

Page S4 


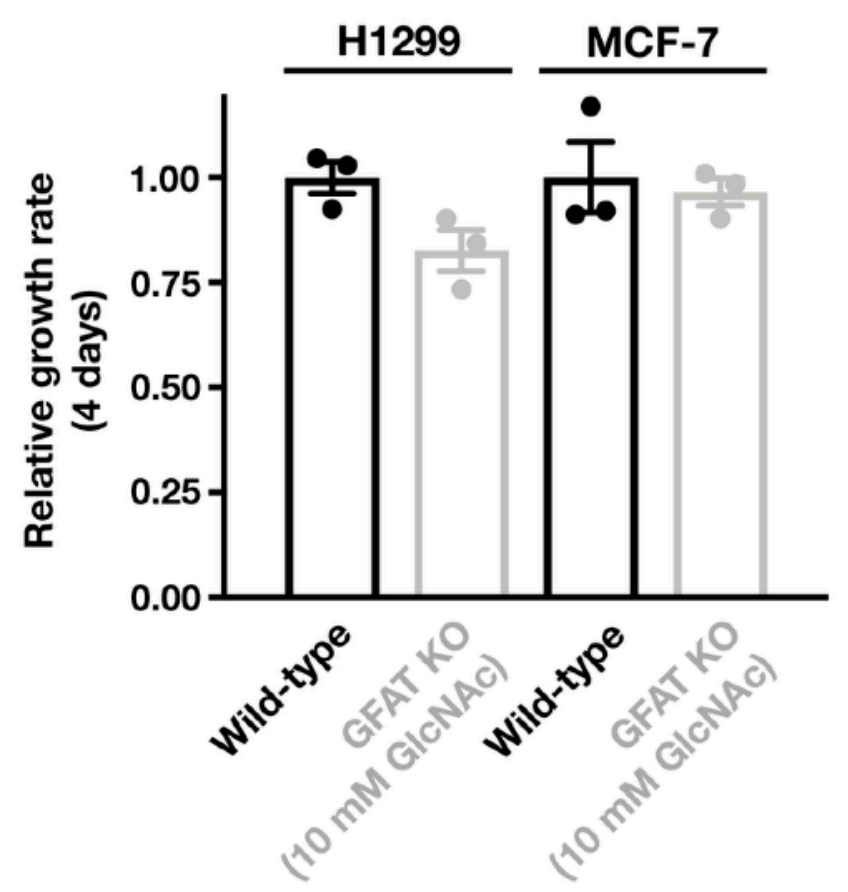

Figure S1. GIcNAc supplementation at $10 \mathrm{mM}$ maintains cell growth with GFAT KO. The same initial number of wild-type or GFAT KO cells with $10 \mathrm{mM}$ GlcNAc were grown for 4 days before the relative growth rates were calculated $(n=3)$.

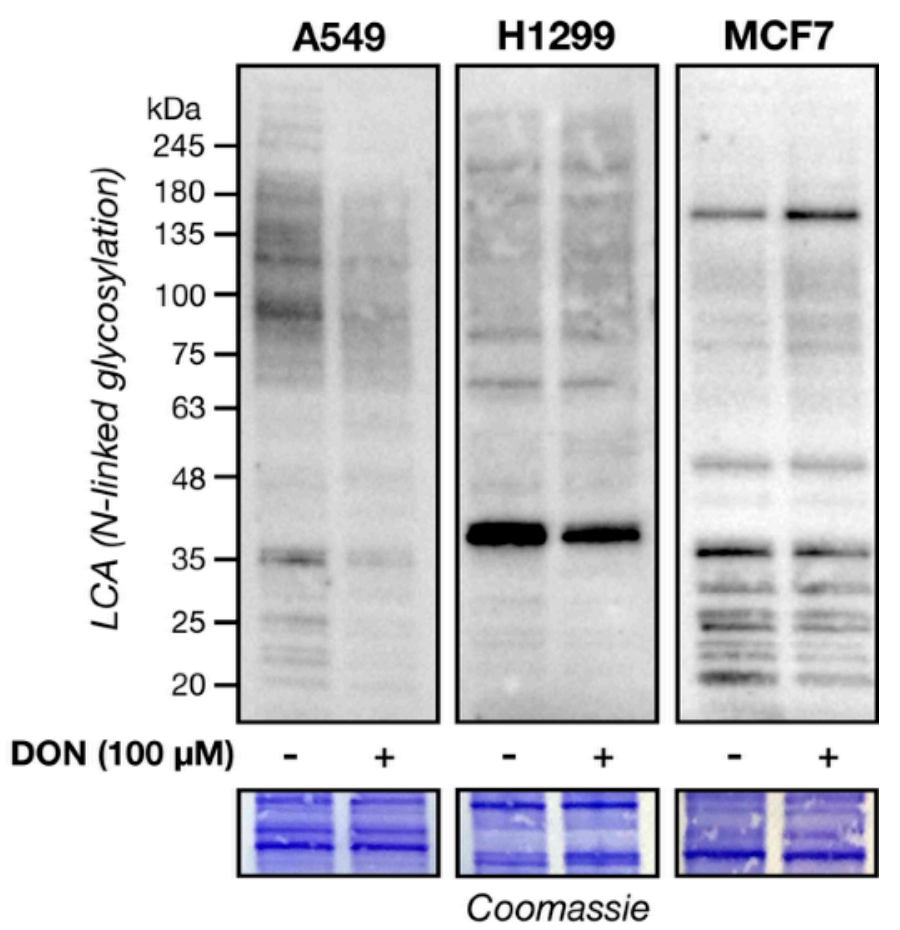

Figure S2. N-linked glycosylation is more resistant than O-GIcNAc to GFAT inhibition. A549, H1299, or MCF7 cells were treated with DON to inhibit GFAT before analysis by LCA lectin-blotting. 


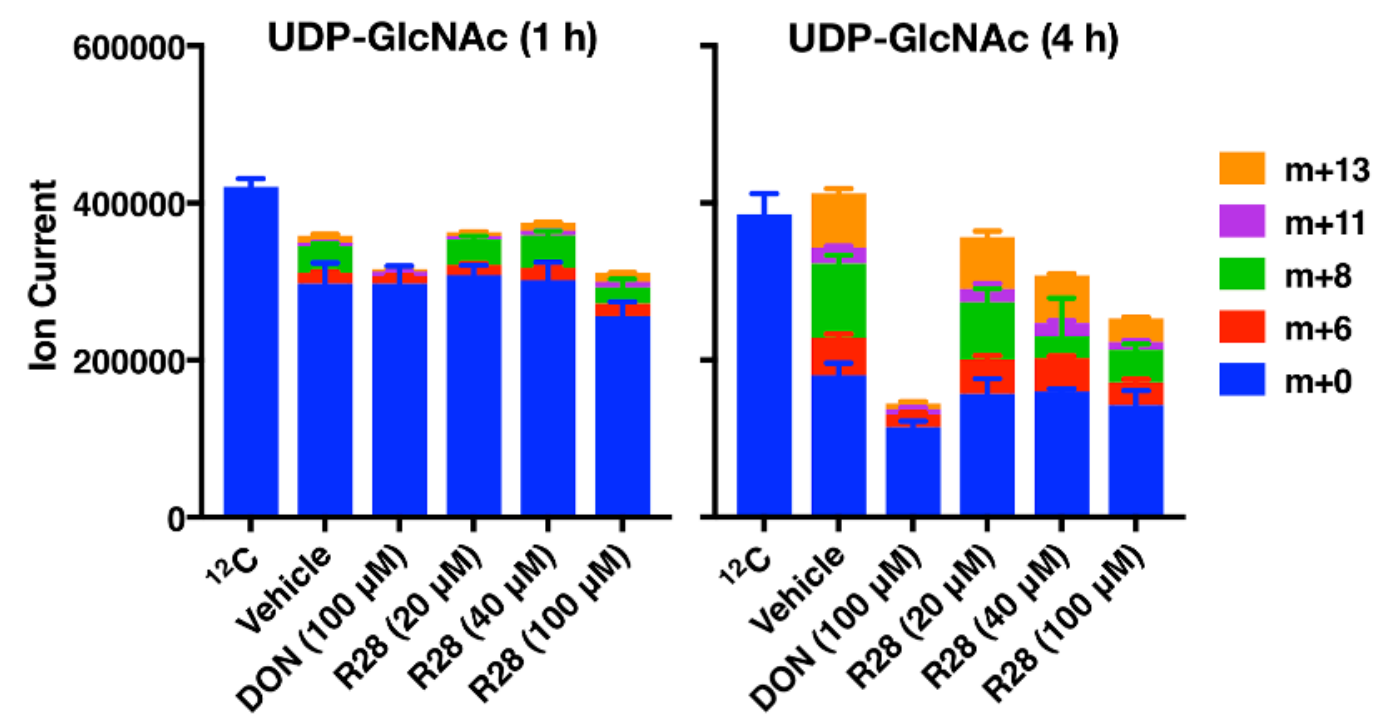

Figure S3. GFAT inhibition reduces flux through the hexosamine biosynthetic pathway. Metabolic flux through the hexosamine biosynthetic pathway in $\mathrm{H} 1299$ cells was determined by measuring incorporation of universally labeled ${ }^{13} \mathrm{C}$ Glucose into UDP-GlcNAc after 1 or 4 hours incubation with either DMSO, DON, or R28. Unlabeled UDP-GlcNAc is indicated in blue, other colors indicate isotopologues which incorporate label through the GFAT reaction. 

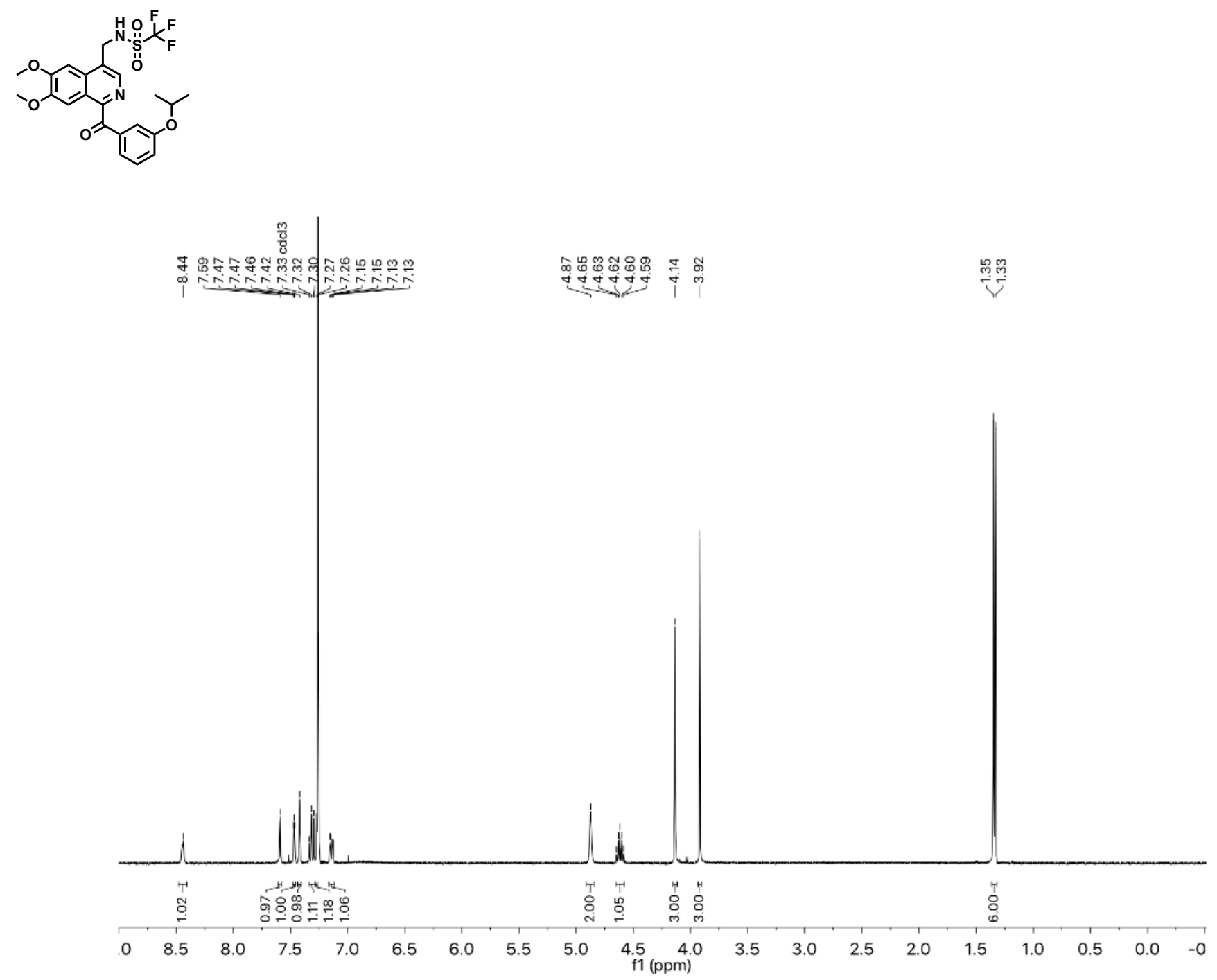

Figure S4. NMR characterization of GFAT inhibitor R28. ${ }^{1} \mathrm{H}$ NMR $\left(500 \mathrm{MHz}, \mathrm{CD}_{3} \mathrm{OD}\right) \delta 8.44(\mathrm{~s}, 1 \mathrm{H}), 7.59(\mathrm{~s}, 1 \mathrm{H})$, $7.47(\mathrm{dd}, J=2.7,1.5 \mathrm{~Hz}, 1 \mathrm{H}), 7.42(\mathrm{~s}, 1 \mathrm{H}), 7.30(\mathrm{q}, J=9.0,8.4 \mathrm{~Hz}, 1 \mathrm{H}), 7.27,(\mathrm{~d}, J=0.8,1 \mathrm{H}), 7.14(\mathrm{dd}, J=7.5,2.6,1 \mathrm{H})$, $4.87(\mathrm{~s}, 2 \mathrm{H}), 4.62(\mathrm{p}, J=6.0 \mathrm{~Hz}, 1 \mathrm{H}), 4.14(\mathrm{~s}, 3 \mathrm{H}), 3.92(\mathrm{~s}, 3 \mathrm{H}), 1.34(\mathrm{~d}, J=6.0 \mathrm{~Hz}, 6 \mathrm{H})$. ESI-MS calcd. for $\mathrm{C}_{3} \mathrm{H}_{23} \mathrm{~F}_{3} \mathrm{~N}_{2} \mathrm{O}_{6} \mathrm{~S}(\mathrm{M}+\mathrm{H})^{+} m / z=513.1$, found $m / z=513.2$. Characterization data agree with previously reported data. 